\begin{tabular}{|c|c|}
\hline & $\begin{array}{l}\text { International Journal of Trend in Scientific } \\
\text { Research and Development (IJTSRD) }\end{array}$ \\
\hline 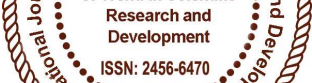 & International Open Access Journal \\
\hline 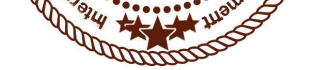 & ISSN No: 2456 - 6470 | www.ijtsrd.com | Volume - 2 | Issue - 2 \\
\hline
\end{tabular}

\title{
The Analysis of Behavioural Finance Theory and its Impacts on Returns on Investment in Selected Businesses in Yola Metropolis Nigeria
}

\author{
Sanusi Bello \\ Department of Business Administration, Faculty of Social and \\ Management Sciences, Adamawa State University Mubi, Nigeria
}

\section{ABSTRACT}

The main aim of this paper is to analyse the behavioural finance theory and its impact on return on investments. Other objectives of this work are to assess the extent to which psychology of the mind of an investor affects investments decisions, and also to examine the behavior of investors and managers toward risk and returns. Also the study identifies how investors design their portfolios according to the rules of their behavior, and investors hope for riches at a lower level of aspirations. The paper gives an insight in understanding how emotions and cognitive errors influence investors and the decision making process. The methodology used for this study was research from the field of psychology in order to have a better understanding of financial decision and create the discipline of behavior finance. Data obtained for the study was through primary source by asking 10 investors that has to do with their behavior and attitude toward risk averse, risk seekers and risk neutral in investments, and secondary sources such as journals from the field of psychology and finance. The method used for analyzing the data was obtained through the use of statistical tools called the Cochran $Q$ test. The study revealed that there was no significant difference between the behavior of investors attitude towards the different kind of risk, investors fear loss of cash in case the business do not augur well for them, they are of the opinion that they only strike on opportunity when it comes their way.

\subsection{Introduction}

Behavior finance has become increasingly growing over the last year, this is as a result of the behavior of an investors. Behavior finance can be said to be the studies of the psychology of any financial decision making, thus an understanding of how the mind of an investors can assist or hinder the success and growth of an investment or investment decisions. These studies have taken a view that theories of finance should take into consideration of observed human behavior. Finance theory focuses on the tradeoff between risk and returns. The theory assumes that investors seek the highest returns for the level of risk they are willing and able to bear. This paper expects behavioral finance to continue to grow in importance, in essence the paper examined the behavior of investors and managers, it describes the outcome of interaction between investors and managers in financial and capital market. It offers alternative bedrock for all the foundation of standard finance, to behavioral finance investors are normal not rational, market are inefficient even if they are very difficult to predict security prices. Therefore all investors in the market do design their portfolios according to the rules of their behavioral portfolio theory and expected returns on their investment follow the behavioral asset pricing theory where risk are not measured by beta $(\beta)$, and expected returns (ER) are determine by risk.

Keywords: Behavior Finance, Investment, Risk, Expected Returns, Portfolio Investors 


\section{Objectives of the Study}

The main objective of the study is to analyse the behavioural finance theory and its impacts on return on investments. The specific objectives of the work are to:

i. Examine the behavior of investors and managers toward risk and returns.

ii. Identify how investors design their portfolios according to the rules of their behavior, and hope for riches at a lower level of aspirations.

\section{Research Questions}

i. In what ways can the behavior of investors and managers toward risk and returns be assessed?

ii. How can investors design their portfolios according to the rules of their behavior, and hope for riches at a lower level of aspirations.

\section{Research Hypotheses}

$\mathbf{H}_{\mathbf{O} 1=}$ There is no any significance difference between Investors attitude toward risk and return

$\mathbf{H}_{\mathbf{O}} \mathbf{2}=$ There is no any significance difference between the behavior of investors biases toward Returns on Investment (ROI).

\subsection{Literature Review}

Behavioral finance in this paper is seen as goal based theory, where all investors divide their wealth into many mental account layers of a portfolio pyramid corresponding to goals such as secure retirement, school fees, or being rich enough to cruise whatever pleases their minds. Friedman \& Savage, (1948) viewed that hope for riches and protection from poverty share roles in our behavior, people who buy lottery tickets often buy insurance policies as well, therefore people are found to be more risk seeking to buy lottery tickets while they are risk averse enough to buy insurance policy.

Friedman \& Savage, (1948) further observed that people who buy lottery tickets because they aspire to reach high social classes, whereas they buy insurance as protection against falling into lower social classes. Markowitz, (1952b) gives clarification of the Friedman \& Savage by noting that people or investor aspire to move up from their current social class or customary wealth. Kahneman \& Tversky, (1979) extended the work of Markowitz (1952) into what is known as prospect theory.
Prospect theory describes the behavior of investors who accepts lottery - like odds when they are below their level of aspirations, but rejects such odds when they are above their level of aspirations. In the other part of this paper the financial theory based on modern portfolio theory Markowitz (1952) and that of Capital Asset Pricing Model (CAPM) Sharp, 1964 paved a way for academicians and investors to analyse investment to see if it is worthwhile or not. The theory is based on the fact that investors are rational and information regarding security price are readily available to all investors in decision making process, therefore investment markets are efficient.

Behavioral finance studies the psychology of financial decision-making. Most people know that emotions affect investment decisions. People in the industry commonly talk about the role greed and fear play in driving stock markets. Behavioral finance extends this analysis to the role of biases in decision making, such as the use of simple rules of thumb for making complex investment decisions Shefrin H, (2000). In other words, behavioral finance takes the insights of psychological research and applies them to financial decision-making. The models within the traditional finance paradigm assume that investors act rationally and consider all available information in the decisionmaking process.

Hence, investment markets are efficient and security prices reflect the true 'intrinsic values' of the assets. That investors act promptly to new information and update prices correctly within a normatively acceptable process. Investment market returns are believed to follow a random walk pattern; hence considered not predictable. Underlying all these is the theory if arbitrage, which suggests that rational investors undo price deviation away from the fundamental values quickly and maintain market equilibrium. As such, 'prices are right' reflecting all available information and there is no 'free lunch': no investment strategy can earn excess risk-free rate of return greater than that warranted by its risk (Fama, 1965). The Modern Portfolio Theory (MPT), Capital Asset Pricing Model (CAPM) and Arbitrage Pricing Theory (APT) are the quantitative models that underpin the rational expectations based theories (Markowitz, 1995; Sharpe, 1964; Ross, 1976).

Unfortunately, there is a large amount of research which could not confirm this theory in the available investment data. For example, Fama and French, $(1993,1996)$ and others have shown that the basic facts about the aggregate stock market, the cross- 
section average returns and individual trading behaviour are not easily understood in this framework. Major property research in this area includes papers by Miles and McCue (1984), Titman and Warga (1986), Lusht (1988) and Liu and Mei, (1992) as such, the behavioural finance paradigm has emerged in the response to the difficulties faced by the traditional paradigm. In essence, it argues that investment choices are not always made on the basis of full rationality, and it attempts to understand the investment market phenomena by relaxing the two doctrines of the traditional paradigm, that is, (1). Agents fail to update their beliefs correctly and (2). There is a systematic deviation from the normative process in making investment choices. The expectations based models argue that the above described irrationality will be undone through the process of arbitrage (Friedman, 1953). Behavioural finance argues that there is 'limits to arbitrage', which allows investor irrationality to be substantial and have long-lived impact on prices.

To explain investor irrationality and their decisionmaking process, behavioural finance draws on the experimental evidence of the cognitive psychology and the biases that arise when people form beliefs, preferences and the way in which they make decisions, given their beliefs and preferences (Barberis and Thaler, 2003). As such, limit to arbitrage and psychology are seen as the two building blocks of behavioural finance.

Arbitrage is an investment strategy that offers riskless profit at no cost. Traditional finance theorists believe that, any mispricing created by irrational traders (noise traders) in the marketplace, will create an attractive opportunity which will be quickly capitalised on by the rational traders (arbitrageurs) and the mispricing will be corrected. Behavioural theorists show that, strategies required to correct the misprising can both costly and risky; thus, rendering the mispricing unattractive and allowing them to continue. Detailed analysis of this argument can be found in De Long, Shleifer, Summers and Waldmann (1990) and Shelifer and Vishny (1997).

\subsection{Theoretical Literature}

\subsubsection{Human Behavioural Theories}

In order to explain the various irrational investor behaviours in financial markets, behavioural economists draw on the knowledge of human cognitive behavioural theories from psychology, sociology and anthropology. Major theories used include:

\subsubsection{Prospect Theory}

Tversky and Kanheman (1979) by way of developing the Prospect Theory showed how people manage risk and uncertainty. In essence, the theory explains the apparent regularity in human behaviours when assessing risk under uncertainty.

That is, human beings are not consistently risk-averse; rather they are risk-averse in gains but risk-takers in losses. According to Tversky and Kanheman, people place much more weight on the outcomes that are perceived more certain than that are considered mere probable, a feature known as the "certainty effect". People's choice are also affected by 'framing effect'. Framing refers to the way a problem is posed to the decision maker and their 'mental accounting' of that problem. The value maximisation function of the Prospect Theory is different from that of the value maximisation function of MPT. Wealth maximisation is between gains and losses, rather than over the final wealth position as in MPT (Markowitz, 1952). As such, people may make different choices in situations with identical final wealth levels. Critical to the value maximisation is the reference point from which gains and losses are measured. Usually, the status quo is taken as the reference point and changes are measured against it in relative terms, rather than in absolute terms.

\subsection{Judgement Under Uncertainty}

The following theories summarise how people form beliefs under uncertainty.

2.2.1 Overconfidence: Alpert and Raiffa (1982) showed that people are poorly calibrated in estimating probabilities and usually overestimate their precision of the knowledge and ability to do well. People are also overconfidence about good things happening in future than bad. In addition, people overestimate their confidence to the past positive outcomes and usually recall only their successes than their failures.

2.2.2 Fear of Regret: Human beings have the tendency to feel the pain or the fear of regret at having made errors. As such, to avoid the pain of regret, people tend to alter their behaviour, which may end up being irrational at times. Linked with fear of regret is 'cognitive dissonance', which is the mental 
suffering that people experience when they are presented with the evidence that their beliefs have been wrong (Shiller,1995).

Tversky and Kahneman (1974) identified the influence of human heuristics on the decision- making process. Tversky at el. defined heuristic as a strategy that can be applied to a variety of problems and that usually-but not always-yields a correct solution. People often use heuristics (or shortcuts) that reduce complex problem solving to more simple judgmental operations.

Three of the most popular heuristics discussed by Tversky at el. include:

2.2.3 Representativeness heuristic: What is the probability that person $A$ (Steve, a very shy and withdrawn man) belongs to group $B$ (librarians) or $C$ (exotic dancers)? In answering such questions, people typically evaluate the probabilities by the degree to which $A$ is representative of $B$ or $C$ (Steve's shyness seems to be more representative for librarians than for exotic dancers) and sometimes neglect base rates (there are far more exotic dancers than librarians in a certain sample).

\subsubsection{Availability heuristic:}

This heuristic is used to evaluate the frequency or likelihood of an event on the basis of how quickly instances or associations come to mind. When examples or associations are easily brought to mind, this fact leads to an overestimation of the frequency or likelihood of this event. Example: People are overestimating the divorce rate if they can quickly find examples of divorced friends.

\subsubsection{Anchoring and adjustment:}

People who have to make judgments under uncertainty use this heuristic by starting with a certain reference point (anchor) and then adjust it insufficiently to reach a final conclusion. Example: If you have to judge person's productivity, the anchor for your final (adjusted) judgement may be your own level of productivity. Depending on your own level of productivity you might therefore underestimate or overestimate the productivity of this person.

\subsubsection{Important Heuristics}

Affect: The affect heuristic concerns 'goodness' and 'badness'. Affective responses to a stimulus occur rapidly and automatically, note how quickly you sense the feelings associated with the stimulus words treasure or hate.

Availability: Availability is a cognitive heuristic in which a decision maker relies upon knowledge that is readily available rather than examine other alternatives or procedures.

Similarity: The similarity heuristic leads us to believe that 'like causes like' and 'appearance equals reality'. The heuristic is used to account for how people make judgments based on the similarity between current situations and other situations or prototypes of those situations.

\subsection{How behavioral biases affect investment decisions}

\subsubsection{Overconfidence}

Psychology has found that humans tend to have unwarranted confidence in their decision making. In essence, this means having an inflated view of one's own abilities. This trait appears universal, affecting most aspects of our lives. Researchers have asked people to rate their own abilities, for example in driving, relative to others and found that most people rate themselves in the top third of the population. Few people rate their own abilities as below average, although obviously $50 \%$ of all drivers are below average. Many studies - of company CEOs, doctors, lawyers, students, and doctors' patients - have also found these individuals tend to overrate the accuracy of their views of the future.

In practical terms, human beings tend to view the world in positive terms. While this behaviour can be valuable - it can help you recover from life's disappointments more quickly - it can also cause an ongoing source of bias in money-related decisions. Barber and Odean (1999), 'The courage of misguided convictions.

\subsubsection{Overconfidence and investing}

Overconfidence has direct applications in investment, which can be complex and involve forecasts of the future. Overconfident investors may overestimate their ability to identify winning investments. Traditional financial theory suggests holding diversified portfolios so that risk is not concentrated in any particular area.

'Misguided conviction' can weigh against this advice, with investors or their advisers 'sure' of the good 
prospects of a given investment, causing them to believe that diversification is therefore unnecessary. Overconfidence is linked to the issue of control, with overconfident investors for example believing they exercise more control over their investments than they do. In one study, affluent investors reported that their own stock-picking skills were critical to portfolio performance. In reality, they were unduly optimistic about the performance of the shares they chose, and underestimated the effect of the overall market on their portfolio's performance. In this simple way, investors overestimate their own abilities and overlook broader factors influencing their investments.

\subsubsection{Too much trading}

Investors with too much confidence in their trading skill often trade too much, with a negative effect on their returns. Professors Brad Barber and Terry Odean studied U.S investors with retail brokerage accounts found that more active traders earned the lowest returns. Whatever insight the traders think they have, they appear to be overestimating its value in investment decisions.

\subsection{Portfolio turnover and return}

\subsubsection{Skill and luck}

Overconfidence may be fuelled by another characteristic known as 'self-attribution bias'. In essence, this means that individuals faced with a positive outcome following a decision, will view that outcome as a reflection of their ability and skill. However, when faced with a negative outcome, this is attributed to bad luck or misfortune. This bias gets in the way of the feedback process by allowing decisionmakers to block out negative feedback and the resulting opportunity to improve future decisions.

\subsubsection{Loss Aversion}

\subsection{Attitudes to risk and reward}

Established financial theory focuses on the trade-off between risk and return. Risk from this perspective means variability of outcomes and riskier investments should, broadly speaking, offer higher rates of return as compensation for higher risk. The theory assumes that investors seek the highest return for the level of risk they are willing and able to bear. Financial advisers often ask clients to complete a risk attitude questionnaire to establish their attitude to risk, and consider issues such as investment time horizon and wealth levels to establish risk tolerance. Risk tolerance drives the types of investments they recommend for the investor.

\subsubsection{Fear of loss}

Behavioural finance suggests investors are more sensitive to loss than to risk and return. Some estimates suggest people weigh losses more than twice as heavily as potential gains. For example, most people require an even $(50 / 50)$ chance of a gain of $£ 2,500$ in a gamble to offset an even chance of a loss of $£ 1,000$ before they find it attractive.

The idea of loss aversion also includes the findings that people try to avoid locking in a loss. Consider an investment bought for $£ 1,000$, which rises quickly to $£ 1,500$. The investor would be tempted to sell it in order to lock-in the profit. In contrast, if the investment dropped to $£ 500$, the investor would tend to hold it to avoid locking in the loss. The idea of a loss is so painful that people tend to delay recognising it. More generally, investors with losing positions show a strong desire to get back to break even. This means the investor shows highly risk-averse behaviour when facing a profit (selling and locking in the sure gain) and more risk tolerant or risk seeking behaviour when facing a loss (continuing to hold the investment and hoping its price rises again).

\subsubsection{The disposition effect}

Professors Shefrin and Statman developed the idea of loss aversion into a theory called the 'disposition effect', which indicates that individuals tend to sell winners and hold losers. In later research, Professors Barber and Odean tested this idea using data from a US retail brokerage. They found that investors were roughly $50 \%$ more likely to sell a winning position than a losing position, despite the fact that US tax regulations make it beneficial to defer locking in gains for as long as possible, while crystallising tax losses as early as possible. They also found that the tendency to sell winners and hold losers harmed investment returns.

\subsection{The problem of inertia}

\subsubsection{Regret avoidance}

Inertia means that people fail to get around to taking action, often even on things they want or have agreed to do. A related issue is a tendency for emotions to sway you from an agreed course of action - 'having second thoughts'. The human desire to avoid regret drives these behaviours. Inertia can act as a barrier to effective financial planning, stopping people from 
saving and making necessary changes to their portfolios.

A fundamental uncertainty or confusion about how to proceed lies at the heart of inertia. For example, if an investor is considering making a change to their portfolio, but lacks certainty about the merits of taking action, the investor may decide to choose the most convenient path - wait and see. In this pattern of behaviour, so common in many aspects of our daily lives, the tendency to procrastinate dominates financial decisions.

\subsubsection{Overcoming inertia with an autopilot}

In recent years behavioural researchers have designed 'autopilot' systems to counteract inertia. For example, in the realm of retirement planning it has been observed that many individuals fail to join their company pension plan, possibly as a result of inertia. Changing the pension scheme so that employees are automatically enrolled in the scheme, while retaining a right to opt out, tends to boost take up rates considerably. In effect, the automatic enrolment approach puts inertia to a positive use. Automatic enrolment is planned for use in the UK's new pension regulations, due to be implemented in 2012. Individuals in pension plans are also often found to be saving at low rates that are unlikely to generate the levels of retirement income the individuals would hope for.

\subsection{Autopilot approaches to investing}

Autopilot approaches can also have relevance in investing, such as taking a disciplined approach to portfolio rebalancing, or a commitment to regular monthly savings. Such disciplined approaches - often called 'commitment devices' by behavioural economists - can help investors avoid biases like overconfidence and promote rational investor behaviour.

In terms of rebalancing, using a regular schedule for guiding decisions can help investors to avoid being swayed by current market conditions, recent performance of a 'hot' investment or other fads. It results in a regular strategy that sells out of markets or investments that have recently outperformed and adds to markets or investments that have lagged. Regular investing, the process of 'pound cost averaging, also helps as the investor tends to accumulate more units or shares of an investment when markets are low than when they are high.

\subsection{Constructing Portfolios}

\subsubsection{Framing}

Finance theory recommends we treat all of our investments as a single pool, or portfolio, and consider how the risks of each investment offset the risks of others within the portfolio. We're supposed to think comprehensively about our wealth. Rather than focusing on individual securities or simply our financial assets, traditional financial theory believes that we consider our wealth comprehensively, including our house, company pensions, government benefits and our ability to produce income.

However, human beings tend to focus overwhelmingly on the behaviour of individual investments or securities. As a result, in reviewing portfolios investors tend to fret over the poor performance of a specific asset class or security or mutual fund. These 'narrow' frames tend to increase investor sensitivity to loss. By contrast, by evaluating investments and performance at the aggregate level, with a 'wide' frame, investors tend to exhibit a greater tendency to accept short-term losses and their effects.

\subsubsection{Mental accounting}

Our psychological self thinks about money and risk through /'mental accounts' - separating our wealth into various buckets or pools. We often base these pools on goals or time horizon (such as 'retirement' or 'school fees'). Accounts can also vary in risk tolerance, investing some in risky assets for gain while treating others more conservatively.

Investors pay less attention to the relationship between the investments held in the different mental accounts than traditional theory suggests. This natural tendency to create mental buckets also causes us to focus on the individual buckets rather than thinking broadly, in terms of our entire wealth position.

\subsection{Behavioural portfolio theory}

In some early versions of portfolio theory, economists suggested that most investors seek to balance security with the small chance for big winnings. Thus portfolio allocations should be based on a combination of 'insurance' (protection against losses) and 'lotteries' (small odds of a large gain). Behavioural economists Shefrin and Statman formalised this approach in their behavioural portfolio theory based on mental accounts. They view behavioural portfolios as being formed of a layered pyramid, with each layer a separate mental account. The base layers represent assets designed to provide 'protection from poverty', which results in conservative investments designed to 
avoid loss. Higher layers represent 'hopes for riches' and are invested in risky assets in the hope of high returns. This idea explains why an individual investor can simultaneously display risk-averse and risktolerant behaviour, depending on which mental account they're thinking about. This model can help explain why individuals can buy at the same time both 'insurance' such as gilts and 'lottery tickets' such as a handful of small-cap stocks. The theory also suggests that investors treat each layer in isolation and don't consider the relationship between the layers. Established finance theory holds that the relationship between the different assets in the overall portfolio is one of the key factors in achieving diversification.

\subsection{Methodology}

The methodology used for this study was research from the field of psychology in order to have a better understanding of financial decision and create the discipline of behavior finance. Data obtained for the study was through primary source by asking 10 investor in different kind of businesses, questions that has to do with their behavior and attitude toward risk averse, risk seekers and risk neutral in investments, and secondary sources such as journals from the field of psychology and finance. The method used for analyzing the data obtained is through the use of statistical tools called the Cochran Q test. It is a tools that is meant to evaluate data of nominal scale or characteristics. These scale can be in form of Yes or No, Effective or Ineffective, Good or Bad, Likes or Dislikes, etc.for the purpose of these study the weight attached to these scale are Yes $=1$ and $\mathrm{No}=0$.

The Cochran $\mathrm{Q}$ test is given by:

$\mathrm{Q}=(\mathrm{K}-1)\left[\mathrm{K}\left(\delta \mathrm{s}^{2}{ }_{1}+\varepsilon \mathrm{S}^{2}{ }_{2}+\ldots \ldots \ldots \ldots+\varepsilon \mathrm{S}^{2}{ }_{\mathrm{K}}\right]-\varepsilon \mathrm{L}^{2}\right] /$ $\mathrm{K}(\varepsilon \mathrm{L})-\varepsilon \mathrm{L}^{2}$

Where $\mathrm{K}=$ Number of samples

$\varepsilon S_{K}=$ sum of favourable responses to each samples

$\delta \mathrm{L}=$ / sum of favourable responses from all respondents in all the samples

$1=$ assigned to $\mathrm{Yes}$

$0=$ assigned to No

\subsection{Result and Discussions}

4.1 Hypothesis 1: To test whether there is a difference in the behavior of investor and attitude towards risk.

\begin{tabular}{|c|c|c|c|c|c|}
\hline $\begin{array}{l}\text { Respondent } \\
\text { (Investors) }\end{array}$ & Risk Averse & Risk Neutral & Risk Seekers & SV & $\mathbf{S V}^{2}$ \\
\hline Chemist & $1 \%$ & 1 Develc & onent & 2 & 4 \\
\hline Phone cards & 0 & 1 & 0 & $1<$ & 1 \\
\hline Restaurants & 0 & $0 \mathrm{LSSN}=2 \mathrm{H}$ & $1-6470$ & 10 & 1 \\
\hline Confectionaries & 1 & 0 & 0 & 10 & 1 \\
\hline Photo Studio & 1 & 10 & 0 & 2 & 4 \\
\hline VideoCoverage & 0 & 0 & 10 & 2 & 1 \\
\hline BusinessCentres & 1 & $1>$ & 0 & 2 & 4 \\
\hline Tailoring & 0 & $1-7 \times$ & 0 & 1 & 1 \\
\hline Transportation & 1 & nonger & 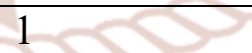 & 2 & 4 \\
\hline Cosmetics & 1 & 00 & 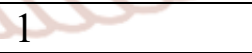 & 2 & 4 \\
\hline Total & 6 & 5 & 4 & 15 & 25 \\
\hline (Total) $^{2}$ & 36 & 25 & 16 & 77 & \\
\hline
\end{tabular}

Source: Field Work, 2015

Using Cochran $\mathrm{Q}$ test

$\mathrm{Q}=(\mathrm{K}-1)\left[\mathrm{K}\left(\sum \mathrm{s}^{2}{ }_{1}+\sum \mathrm{S}^{2}{ }_{2}+\ldots \ldots \ldots \ldots+\varepsilon \mathrm{S}^{2}{ }_{\mathrm{K}}\right]-\delta \mathrm{L}^{2}\right] / \mathrm{K}\left(\sum \mathrm{L}\right)-\varepsilon \mathrm{L}^{2}$

$\mathrm{Q}=3-1[3(36+25+16]-225] / 3(15)-25$

$\mathrm{Q}=2[3(77-225)] / 20$

$\mathrm{Q}=2[231-225] / 20$

$\mathrm{Q}=2(6) / 20$

$\mathrm{Q}=12 / 20$

$\mathrm{Q}=0.60$ 
The critical value of $Q$ at 0.05 level of significance at (3-1) degree of freedom is 5.99 from the $X^{2}$ table. Since the calculated value of $Q=0.60$ is less than the critical value of 5.99, we cannot reject the null hypothesis. It is therefore conclude that there is no significance difference in the behavior of Investors attitude towards risk.

4.2 Hypothesis 2: To test whether there is a difference between the behavior of investors/managers biases and Return on Investment.

\begin{tabular}{|l|l|l|l|l|l|}
\hline $\begin{array}{l}\text { Respondent } \\
\text { (Investors) }\end{array}$ & Overconfidence & $\begin{array}{l}\text { Toomuch } \\
\text { trading }\end{array}$ & $\begin{array}{l}\text { Inertia } \\
\text { problems }\end{array}$ & SV & SV $^{2}$ \\
\hline Risk neutral & 1 & 1 & 0 & 2 & 4 \\
\hline $\begin{array}{l}\text { Risk } \\
\text { avoidance }\end{array}$ & 0 & 1 & 0 & 1 & 1 \\
\hline Risk seekers & 0 & 0 & 1 & 1 & 1 \\
\hline Total & $\mathbf{1}$ & $\mathbf{2}$ & $\mathbf{1}$ & $\mathbf{4}$ & $\mathbf{6}$ \\
\hline (Total) $^{\mathbf{2}}$ & $\mathbf{1}$ & $\mathbf{4}$ & $\mathbf{1}$ & $\mathbf{6}$ & \\
\hline
\end{tabular}

Source: Field Work, 2015

Using Cochran Q test

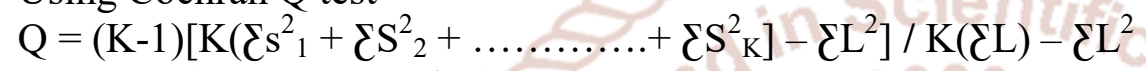

$\mathrm{Q}=3-1[3(1+4+1]-16] / 3(4)-6$

$\mathrm{Q}=2[3(6-16)] / 6$

$\mathrm{Q}=2[-30] / 6)$

$\mathrm{Q}=-60 / 20$

$\mathrm{Q}=-3$

The critical value of $Q$ at 0.05 level of significance at (3-1) degree of freedom is 5.99 from the $X^{2}$ table. Since the calculated value of $Q=-3.0$ is less than the critical value of 5.99, we cannot reject the null hypothesis. It is therefore conclude that there is no significance difference in the behavior of Investors/managers biases towards return on investment risk.

\subsection{Conclusion}

This paper the analysis of behaviuoral finance theory and its impacts on returns on investment in some selected businesses in Yola Metropolis. Behavior finance is expected to continue to grow in importance, the paper examines the behavior of investors and managers, it describe the outcome of interaction between investor sand managers in financial and capital market. Therefore all investor in the market do design their portfolios according to the rules of their behavior portfolio theory and expected returns. The paper is also seen as a goal based theory where all investors divide their wealth into many mental account layers of portfolio pyramid corresponding to goal such as school fees, secure retirement, or being rich enough to cruise whatever pleases their minds Friedman \& Savage (1948) opined that hope for riches and protection from poverty share roles in our behavior, people who buys lottery tickets often buys insurance policies as well, therefore, people are found to be more risk seeking to buy lottery tickets while they are risk averse enough to buy insurance policy.

\section{References}

1. Fama, e.f. 1991. "efficient capital markets." Journal of finance, vol. 46, no. (december):15751617

2. Fama, e.f. 1965. "random walks in stock market prices." Financial analysts journal, vol. 21, no. 5 (september/october):55-59.

Doi:10.2469/faj.v21.n5.55

3. Fama, e.f., and k. French. 1992. "the cross-section of expected stock returns." Journal of finance, vol. 47, no. 2 (june):427-465.

4. Fair, r. 2002. "the events that shook the market." Journal of business, vol. 75, no. 4 (october):713731. Doi: $10.1086 / 341640$

5. Friedman, m., and 1. Savage. 1948. "the utility analysis of choices involving risk." Journal of political economy, vol. 56, no. 4 (august):279304.

6. Kahneman, d., and a. Tversky. 1979. "prospect theory: an analysis of decision under risk." Econometrica, vol. 47, no. 2 (march):263-291. 
7. Mangalindan, m. 2002. "hoping is hard in silicon valley." Wall street journal (july 15): cl.

8. Markowitz, h.m. 1952a. "portfolio selection." Journal of finance, vol. 7, no. 1 (march):77-91.

9. Markowitz, h.m 1952b. "the utility of wealth." Journal of political economy, vol. 60 , no. 2 (april):151-158.

10. Markowitz, h.m. 1959. Portfolio selection: diversification of investments. New york: john wiley \& sons.

11. Markowitz, h.m. 1999. "the early history of portfolio theory: 1600-1960." Financial analysts journal, vol. 55, no. 4 (july/august):5-15.

12. Miller, M.H. 1986. "Behavioral Rationality in finance: the case of dividends." Journal of business, vol. 59, no. 4 (october):s451-s468.

13. Miller, M., and F. Modigliani. 1961. "dividend policy, growth, and the valuation of shares." Journal of business, vol. 34 , no. 4 (october): $411-$ 433.

14. Pontiff, J. 2006. "costly arbitrage and the myth of idiosyncratic risk." Journal of accounting and economics, vol. 42 , no. 1-2 (october):35-52.

15. Sharpe, W.F. 1964. "capital asset prices: a theory of market equilibrium under conditions of risk." Journal of finance, vol. 19 , no. 3 (september):425442.
16. Shefrin, H.M., and M. Statman. 1984. "explaining investor preference for cash dividends." Journal of financial economics, vol. 13, no. 2 (june):253282.

17. Shefrin, H.M., and M. Statman. 1985. "the disposition to sell winners too early and ride losers too long: theory and evidence." Journal of finance, vol. 40 , no. 3 (july):777-790.

18. Shefrin, H.M., and M. Statman. 1994. "behavioral capital asset pricing theory." Journal of financial and quantitative analysis, vol. 29, no. 3 (september):323-349.

19. Shefrin, H.M., and mM. Statman. 2000. "behavioral portfolio theory." Journal of financial and quantitative analysis, vol. 35 , no. 2 (june):127-151.

20. Snyder, WH..T. 1957. "how to take a loss and like it." Financial analysts journal, vol. 13, no. 2 (may):115-116. Doi:10.2469/faj.v13.n2.115

21. Statman, M. 2005. "Martha Stewart's lessons in behavioral finance." Journal of investment consulting, vol. 7, no. 2 (winter):52-60. 